\title{
QUESTIONING THE IMPACT OF IMPACT \\ Evaluating Community-Campus Engagement as Contextual, Relational, and Process Based
}

\author{
Charles Z. Levkoe and Lauren Kepkiewicz
}

\section{Abstract}

As community-campus engagement (CCE) continues to gain momentum, impact has increasingly been evaluated through qualitative measurements rooted in community-based perspectives. However, for CCE to have meaningful impact, it must challenge dominant power structures and work to create equitable relationships. This article explores efforts to better understand and evaluate the impacts of CCE. Based in our research on 12 place-based CCE projects that aimed to support food sovereignty in Canada, the findings bighlight how evaluating impact needs to be contextual, relational, and process-based with a focus on how CCE contributes to or hinders broader social change. Two additional themes supporting increased impact also emerged: the development of collaborative knowledge and actions; and, building networks of CCE communities of practice. The research also identified the limitations of evaluating CCE impact when measurements are pre-determined, top down, and are not rooted in community needs and perspectives. While we believe that evaluating impact can be a meaningful and important process, it is necessary to challenge assumptions that measuring impact is always desirable or possible.

\section{Introduction}

As community-campus engagement (CCE) continues to gain momentum, there have been calls to better understand and evaluate impact well beyond quantitative indicators to include a broader range of approaches (Beckman, Penney, \& Cockburn, 2011; Block, Hague, Curran, \& Rosing, 2018; Wiebe \& Taylor, 2014). For many engaged scholars, this necessarily involves qualitative and subjective measurements rooted in community-based perspectives (Srinivas, Meenan, Drogin, \& DePrince, 2015; Ward \& Wolf-Wendel, 2000). Furthermore, critical scholars have argued that for CCE to have impact, it must challenge dominant power structures and work toward the creation of equitable relationships in relation to both community service-learning (CSL) (Grain \& Lund, 2016; Marullo \& Edwards, 2000; Mitchell, 2008) and community-based research (CBR) (Curwood, Munger, Mitchell, Mackeigan, \& Farrar, 2011; Jagosh et al., 2015; Taylor \& Ochocka, 2017). Building on these calls, this article explores efforts to better understand and evaluate the impacts of CCE. While we believe that 
evaluating impact can be a meaningful and important process, it is necessary to challenge assumptions that measuring impact is always desirable or possible.

Our insights draw on four years of evaluative research as part of the Community First: Impacts of Community Engagement (CFICE) partnership ${ }^{1}$ with 12 place-based CCE projects that occurred between $2012-$ 2016 with the aim of supporting food sovereignty. ${ }^{2}$ Premised on the explicit goal of building healthier, more democratic, and longer-lasting community-campus relationships, this article highlights the ways academics and community-based project partners understood and experienced the impact of CCE on their partnerships as well as on broader food sovereignty movement goals. ${ }^{3}$ Our findings highlight ways that participants described a need for evaluation of impact as contextual, relational, and process-based with a focus on how CCE contributes to or hinders broader social change goals. In order to further unpack these descriptions of CCE impact, we look at two additional themes that emerged from project partners' discussions: (a) the development of collaborative knowledge and actions; and (b) building networks of CCE communities of practice through food movement networks. The research also identified the limitations of evaluating CCE impact when measurements are predetermined, top down, and are not rooted in community needs and perspectives.

In the following sections, we present an overview of literature about the growing attempts to measure CCE impact rooted in community as well as being a potential tool for social change. We then describe our methodology based on our research with 12 CCE projects in more detail. In the next section, which outlines our findings, we share our project partners' reflections on how to meaningfully measure the impact of CCE. We also analyze the specific impacts of the CFICE project partnerships, using a variety of qualitative data gathered over the seven years of CFICE research. In our discussion, we emphasize the need to question the impact of impact. We suggest that it is not always possible or desirable to measure the impact of CCE work, particularly through linear indicators that seek to standardize and quantify outcomes for funding bodies or other actors external to the partnership.

\section{Measuring CCE Impact on Communities}

In 2014, a national summit on CBR, Pursuing Excellence in Collaborative Community Campus Research, was held at the University of Waterloo. One of the summit's goals was to develop indicators for assessing tangible impacts of CBR for both communities and universities. ${ }^{4}$ Writing about the summit's outcomes, Taylor and

1. For more information on CFICE, see https://carleton.ca/communityfirst.

2. Food sovereignty is described as "the right of peoples to healthy and culturally appropriate food produced through ecologically sound and sustainable methods, and their right to define their own food and agriculture systems” (see https://nyeleni.org/spip.php?article290).

3. Food sovereignty goals are rooted in seven core pillars. The first six were developed at the International Forum for Food Sovereignty in Nyéléni, Mali, in 2007: (a) focuses on food for people; (b) builds knowledge and skills; (c) works with nature; (d) values food providers; (e) localizes food systems; and, (f) puts control locally. The seventh pillar-food is sacred—was added by members of the Indigenous Circle during the People's Food Policy process in 2011. See https://foodsecurecanada.org/who-we-are/what-food-sovereignty. 4. The summit was co-hosted by the Community Based Research Canada and the Centre for Community Based Research in Waterloo, Canada. 
Ochocka (2017) emphasized the need for "excellence, standardisation and quality assessment of CBR projects, programs and networks" (p. 185) and in particular the value of "indicators that can be evaluated based on specific measures of practice and performance" (p. 189). From the summit, CBR impact was described as "creative and effective strategies for both mobilising knowledge (Phipps, 2011) and mobilising people (Kemmis \& Mc Taggart, 2005 ) to increase positive individual, community, and societal impacts” (Taylor \& Ochocka, 2017, p. 193).

Conference participants from universities, government, and community organizations identified key strengths for assessing CCE impact that included improving research rigor and best practices, meeting peer review requirements, increasing funding success, influencing policy, building community partners' capacity, and countering criticisms of “soft' research and its implication for career advancement” (Wiebe \& Taylor, 2014, p. 5). Preliminary indicators for assessing CBR research rigor and impact were also developed that included a variety of measurable outcomes such as the number of new connections made, the number of community members who contribute to knowledge development, and the creation of research reports that inform policy. Overall, the summit report emphasized that current criteria for assessing CBR should be redefined and that societal impacts be evaluated through both quantitative and qualitative measurements (Impact, n.d., p. 5). This follows a more general move from understandings of CBR impact that are measured primarily through scholars' contributions to their academic fields of study toward an approach to evaluation that includes social, economic, environmental and cultural changes among communities themselves (Duryea, Hochman, \& Parfitt, 2007; Penfield, Baker, Scoble, \& Wykes, 2014).

Similarly, scholars have argued for a shift in assessing CSL impact. Traditionally, CSL impact has focused on enhancing student experiences and outcomes such as improving learning environments, professional skills, academic knowledge, civic engagement, and social behavior and attitudes (see, e.g., Celio, Durlak, \& Dymnicki, 2011; Cruz \& Giles, 2000; Eyler, Giles, Stenson, \& Gray, 2001). Additionally, Curwood et al. (2011) note that universities should "be mindful of the possible impact on the community of poorly conceived and badly executed partnerships” (p. 24), particularly in a context where university research has often exploited communities. In response, there have been calls for more rigorous assessments of CSL impact that focus directly on the effects of communities involved (Beckman et al., 2011; Block et al., 2018; Blouin \& Perry, 2009; Vernon \& Ward, 1999; Ward \& Wolf-Wendel, 2000).

\section{Evaluating CCE as Social Change}

CCE has been championed by some as contributing to progressive social change through building respectful research and teaching relationships (Bringle \& Hatcher, 2002; Collins et al., 2018; Ochocka \& Janzen, 2014). However, scholars have cautioned that CCE has also served to reinforce inequitable power dynamics favoring academics and their institutions over community interests and broader social needs (Bortolin, 2011; Cronley, Madden, \& Davis, 2015; Curwood et al., 2011; Mitchell, Donahue, \& Young-Law, 2012; Sheridan \& Jacobi, 2014; Verjee, 2012; Vernon \& Ward, 1999). For example, Cahuas and Levkoe's (2017) study of CSL found that classrooms are not always conducive to addressing issues of race and racism. They explained that even though 
critical CCE can provide opportunities to challenge power hierarchies, it is "limited in its capacity to achieve social transformation, as it is mired in the very power structures it attempts to challenge” (p. 259). Citing similar concerns, Grain and Lund (2016) underline the ways that CCE is often "steeped in a history of White normativity and charity" that risks exacerbating inequities by placing excessive work on marginalized activists (p. 46). Furthermore, scholars have voiced concerns about the ways that CCE can put undue responsibility onto communities that are already dealing with issues of social marginalization (Guta, Flicker, \& Roche, 2013; MacLeod $\&$ Emejulu, 2014) as well as providing an avenue for academics and government funders to achieve self-serving agendas (Trickett \& Beehler, 2017; Varcoe, 2006).

Beyond the rhetoric of apolitical social change discourse, a growing group of scholars have envisioned CCE as a process that has the potential to challenge inequitable power dynamics, increase community well-being, and encourage systemic change (Kepkiewicz, Levkoe, \& Brynne, 2018; Marullo \& Edwards, 2000; Mitchell, 2007; Sheridan \& Jacobi, 2014; Taylor \& Ochocka, 2017). Grain and Lund (2016) suggest this must include incorporating social justice principles into CCE work and ensuring leadership and action emerges directly from community-academic collaborations. To avoid CCE that reproduces and exacerbates inequities, Verjee (2012) argues for the increased use of critical race theory to address white supremacy within both universities and communities. For example, she stresses the need for structural change and institutional transformations, including anti-oppression training, hiring more people of color as faculty and non-academic staff, as well as suggesting that university-community partnerships need to ensure that those who are most marginalized are central to partnership developments at all levels. Kepkiewicz, Srivastava, Levkoe, Brynne, and Kneen (2017) argue for the use of critical Indigenous studies frameworks within CCE to address issues of Indigenous sovereignty and settler colonialism in a Canadian context. These perspectives suggest that an evaluation of CCE impact should be rooted in social justice frameworks that support assessments of CCE impact that capture both positive and negative effects of research and teaching from an intersectional perspective as well as contributions (or barriers) to social transformation and structural change. The use of these frameworks for assessing CCE emphasizes the need to understand impact in relation to a variety of lived experiences, both within and between community and university partners.

In summary, literatures on both CBR and CSL have increasingly emphasized the need for more standardized indicators and rigorous assessments as well as the need to consider impact in relation to the experiences of communities and the ongoing alignment of proximate outcomes to broader goals of social change. While we welcome this turn in evaluating CCE (and in particular the emphasis on impact as social change), we are cautious about academic attempts to standardize CCE assessments and develop universal measurements. In this article, our research builds on these shifting perspectives to consider how to better understand and evaluate the impacts of CCE as contextual, relational, and process based with a focus on the ways that CCE might contribute to and/ or hinder social change. 


\section{Methodology and Methods}

The data presented in this article is based on research conducted through the CFICE research partnership. Findings emerged from an analysis of the final reports from 12 CCE projects, transcripts from post-project interviews, and reflections from the authors of this article who were both academic members of the Community Food Security/Sovereignty (CFS) hub management team. Funded by the Social Sciences and Humanities Research Council of Canada, this pan-Canadian participatory action research investigated "ways that CCE partnerships can be designed and implemented to maximize the value created for non-profit, community-based organizations" (CFICE, n.d.). During Phase I (2012-2016) of CFICE, the project was organized into five thematic hubs, focusing on CFS, poverty reduction, violence against women, environmental sustainability, and knowledge creation. Each hub was led by community and academic co-leads that worked together to shape the activities and objectives that were most appropriate to the partners involved. During Phase II of CFICE, working groups were established to address emerging cross-hub themes.

During Phase I, the CFS hub worked with its core partners, Food Secure Canada ${ }^{5}$ (FSC) and the Canadian Association of Food Studies ${ }^{6}$ (CAFS) as well as over 30 community and academic organizations to explore the possibilities of putting community-first CCE into practice. For the CFS hub, community-first CCE meant taking direction from its core partners and supporting the growing network of community-campus partnerships engaged in food sovereignty research and action. During the early years, potential CCE projects responded to a call for proposals and applied to participate in the CFS hub, whereas in the final two years, key projects were selected by the CFS hub management team to fill gaps in its research. The 12 CCE projects ${ }^{7}$ included the following:

1. Models of Community University Collaboration (Waterloo, Ontario) worked with the Region of Waterloo Public Health and the University of Waterloo to share lessons from different CCE models to advance a vision of community-based food systems.

2. Campus Food Initiative Study (pan-Canadian) worked with Meal Exchange and Ryerson University to examine student-led campus food system initiatives.

3. Cross-Cultural Food Networks: Building and Maintaining Inclusive Food Security Networks to Support Indigenous and Non-Indigenous Communities (British Columbia) worked with the British Columbia Food Systems Network (BCFSN) and the University of Victoria to uncover the factors that enable crosscultural relationships in regional food systems.

\footnotetext{
5. FSC is a is a "pan-Canadian alliance of organizations and individuals working together to advance food security and food sovereignty through three inter-locking goals: zero hunger, healthy and safe food, and sustainable food systems" (FSC, n.d.).

6. CAFS is a pan-Canadian association for academics and professional researchers involved in interdisciplinary scholarship in the broad area of food systems (see www.foodstudies.ca).

7. For more information on the $12 \mathrm{CFS}$ hub projects, see https://carleton.ca/communityfirst/sector-specific-work/community-food-security/. Also see Andrée et al., 2014; Andrée et al., 2016; Kepkiewicz et al., 2017; Levkoe et al., 2016; Levkoe, Brem-Wilson, \& Anderson, 2019; Levkoe, Erlich, \& Archibald, 2019.
} 
4. Local Food Multipliers (Northern Ontario) worked with the Food Security Research Network (FSRN) at Lakehead University and the North Superior Workforce Planning Board to determine the workforce multiplier effects of local food production and processing.

5. Planning for Change: Community Development in Practice (Ontario) worked with Sustain Ontario: The Alliance for Healthy Food and Farming and the University of Toronto to support regional food procurement among municipalities.

6. The Seed Community Food Hub (Guelph, Ontario) worked with the Guelph and Wellington Task Force for Poverty Elimination, the Guelph-Wellington Food Round Table, and the Institute for Community Engaged Research at the University of Guelph to support the development of a regional food hub.

7. The Edible Campus (Montréal, Quebec) worked with Santropol Roulant and McGill University to evaluate the relationship between a community meal program and a university-based urban agriculture initiative.

8. Community Food Assessment (Regina, Saskatchewan) worked with the Regina Qu'Appelle Health Region, the Regina Education and Action on Child Hunger (REACH), and the University of Regina to engage in a participatory process to improve community food systems.

9. Developmental Evaluation (British Columbia) worked with Long-Term Inmates Now in the Community (LINC), the District of Mission, and the University of British Columbia to explore experiences of people transitioning from incarceration through a community agriculture initiative.

10. Sharing the Table: Manitoba Meat Regulations (Manitoba) worked with the University of Manitoba, the Canadian Mennonite University, and Sharing the Table Manitoba to evaluate and expand CCE within an existing collaborative work.

11. Paying for Nutrition: Northern Food Costing (Northern Canada, Ontario, and Nova Scotia) worked with Food Secure Canada, FoodARC, and Lakehead University to utilize and strengthen the existing northern CCE network through food costing and supporting advocacy efforts.

12. Responsibilities and Relationships: Decolonizing the BC Food Systems Network (British Columbia) worked with the British Columbia Food Systems Network (BCFSN) to explore meaningful relationships across Indigenous-settler divides through food sovereignty.

A central component of the CFS hub's engagement with participating projects was to provide a small amount of funding and ongoing support to enhance capacity for self-evaluation of the CCE project. As part of this evaluation, project partners were asked to define and explain the impact and value of CCE on their work in a final report.

These 12 reports formed the basis of the data and analysis for this article. Each varied in length and content, often depending on the objectives of the particular project as well as the capacity of the community and academic partners. We also found that there were differing levels of interest in reflecting and communicating experiences through written communication. In general, the written reports were more detailed in the final two years 
of the project as the CFS hub team learned how to better support each project and communicate expectations in terms of evaluating community-campus partnerships.

In addition to studying the written reports, the analysis of this article also draws from data collected in a series of interviews conducted in 2015. Using a semi-structured interview guide, these discussions focused on how project partners understood the impact of their CCE work. Questions ranged from what participants learned by evaluating CCE to what outcomes arose from their CFS project partnerships. Interviews were requested from all the lead academic and community partners from each project that had been completed or were ongoing in 2015. Interviews were also conducted with academic and community-based practitioners who were members of CFS hub partners Food Secure Canada and the Canadian Association of Food Studies and/or were members of the CFS hub Advisory Committee. Interviews were conducted over the phone by the hub's research assistant as well as a community-based researcher. Where final project reports were lacking in detail, the interviewers spent significantly more time asking community and academic partners to explain their project partnerships and the perceived impacts. Out of the 10 projects included in the interviews, researchers spoke with 14 academics and 12 community practitioners. At least one individual from each project partnership was interviewed. Of note, it was not always possible to interview an academic and community partner from each project due to factors such as maternity leaves, heavy workloads, and illness. Additionally, some partners indicated they did not have anything further to add to what was said in their project report. We did not conduct interviews with the two projects that occurred in the final year of the hub as the reports were written in great detail. While material drawn from the final reports references the specific project, interviews were conducted anonymously, meaning that neither specific projects nor individuals are named in data drawn from these conversations.

In addition to analyzing the 12 final project reports and the interviews, we drew from our own experiences and reflections within the CFS hub management team. The interviews, reports, and CFS hub team reflections were organized into themes by the CFS hub management team. These themes were discussed during multiple meetings as well as in consultation with other CFICE participants. Within the CFS hub, an analytical process was developed in which everyone reviewed the data, met to discuss themes, and then individually coded the different data sets. After each individual had completed coding, the team collectively reviewed the coding to rearrange, add, and offer further insights, suggestions, and themes. In the sections below, we discuss the analytical themes that were identified, using quotations from the interviews as well as excerpts from the final project reports to demonstrate the broader themes that arose from our analysis of the project as a whole.

\section{Defining the Impact of CCE within the Community Food Sovereignty Hub}

While the CFS hub community and academic partners did not always agree on how to explain impact, some common themes emerged from their descriptions. These included ideals that CCE impact should be defined within a project's specific context, by all partners involved, as relational with a focus on process, and through 
measuring short-term objectives along with longer term contributions to social change. In order to further unpack these descriptions of CCE impact, we look at two additional themes that emerged from project partners' discussions - the development of collaborative knowledge and building networks of CCE communities of practice. In doing so, we explore ways that CFS partners described impact within their own CCE projects. Throughout these conversations, participants emphasized the contributions of CCE to partners' specific work as well as to broader social change efforts.

\section{CCE Impact as Context Specific, Relational, and Process based}

Overall, CFS hub project partners explained that evaluations of CCE impact need to be context specific, relational, and process based. Moreover, participants emphasized that impact must be defined by the individuals directly involved in the particular project being evaluated. In this subsection, we present some key examples from our research with the 12 CFS hub projects.

The final report of the Paying for Nutrition project emphasized that in order to make CCE meaningful for communities throughout all aspects of a project, community-based partners need "to be in the driver seat" (CFICE internal report). Similarly, CFS hub partners underlined the need to for all participants involved to assess research impacts in ways that make sense to the specific people and places involved. An academic co-lead from another CFS hub project explained, "We need to evaluate each CCE project separately because they are context specific. Key themes to consider during an evaluation should include reciprocity, communication, trust, and benefits to all partners. All evaluations should be developed by the partners and for the partners." Similarly, another academic project co-lead commented, "We really need to define the terms of evaluation very locally around what is the nature of trust and connection, and what is the nature of the relationship."

In addition to designing an evaluation that looks at both community and university impacts, project partners explained that CCE cannot be evaluated on the basis of a single indicator or outcome but rather needs to be based in the ongoing development of relationships and processes. An academic participant from one of the projects suggested, "When working with community members outside of their comfort zone, we can't really evaluate this in relation to whether it meets a particular predetermined goal or not. Instead we need to take a developmental approach - an approach that recognizes it's a process. ... We need to do evaluation through conversations and interviews in order to see the relationship from different perspectives." The necessity of understanding the impacts from a variety of perspectives was also highlighted in the Cross-Cultural Food Networks project, which emphasized the value of difference. Even when these differences come into conflict, the project's final report acknowledged the positive longer term impacts that can ensue.

Reflecting on the value of impact as process oriented and long-term, CFS hub participants highlighted some of the challenges of capturing impacts within a predetermined time frame. Beyond the support that CFICE was able to provide, many projects where funded on a short-term basis and their evaluations were often geared 
toward funders with the goal of providing quantified evidence of success with the hope of receiving continued funding. They often saw these types of impact assessments as overly simplistic and unhelpful for capturing the complex impacts of CCE projects. When impact was understood as a way to procure funding, participants were explicit about the meaninglessness of these kinds of evaluations, pointing to a lack of community engagement in defining the terms of evaluation. An academic participant discussed some of these challenges related to shortterm funding cycles: "For community-based work the process of change is much longer. For CBR, there is not a single outcome, but the process is the outcome.” In some cases, community partners were disinterested in evaluating impact because they felt it took away from time spent accomplishing program objectives and building longer term relationships. This concern was echoed by an academic participant who explained the difficulty of evaluating CCE impacts with the intention of providing concrete evidence of success for funding bodies: "In this funding environment evaluation becomes about accountability and is measured in short term periods. This makes it difficult to see any real change in this area. To make or see change in food security it must be longer-term.”

Beyond these agreements, some participants differed in discussing their motivations for measuring CCE impacts. Whereas most were primarily interested in how CCE impacts the communities directly involved in their projects, others wanted to understand impacts on broader efforts toward social change. For example, in one project, the community partner identified an implementation plan and final report produced by students as a key impact on the communities they worked with: "The students conducted an environmental scan of municipalities in various countries and then evaluated several local case studies." Through this research a set of best practices were developed along with risks and challenges associated with local food procurement. The final report for the Edible Campus project also highlighted the research and graphic design contributions that McGill graduate students made to the project. It recommended that the community organization involved should "actively develop and maintain relationships with faculty and graduate students who can help produce quality designs, create informational materials, conduct research, and overall, raise awareness about the project within the university community."

While this kind of concrete and short-term impact was of great value, some CFS partners emphasized the need to go beyond these more tangible products in order to meaningfully understand CCE impacts. For example, one academic project co-lead explained, "My experience is that there are no profound short-term gains in CCE work. These gains come years later." Following this sentiment that evaluating CCE should look to longer term impacts, a community co-lead from a different project noted the importance of capturing impacts in relation to social change goals. Discussing the goals of the CCE partnership, she explained, "We wanted to trace the deeper systemic changes within the community so we needed to sit down and really contemplate what we thought we needed to be measuring in order to understand this."

In order to understand whether and how CCE relationships are effective and impactful, the Responsibilities and Relationships project also highlighted the need to look at systemic change and to draw from social and environmental justice frameworks as well as decolonizing grassroots action and theory to understand social change brought about by food sovereignty. For example, in the final report, they note, 
in order to truly support food sovereignty in the region in which we work, we must better understand the impacts of colonization on both Indigenous and settler communities.... There can be no food sovereignty for Canadians until we redesign institutional frameworks to support and implement Aboriginal Title and Rights that will enable Indigenous peoples to protect, conserve and restore the complex system of biocultural heritage in the land and food system as a whole.

\section{CCE Impact as Collaborative Knowledge and Action}

Building on these descriptions of impact as context specific, relational, and process based, this subsection focuses on CFS partners' description of impact through the development of collaborative knowledge about CCE partnerships, food systems, and social change.

The final report from the Sharing the Table project pointed to the ways that CCE brought different kinds of knowledge together; while this caused tensions at times, it also generated new insights. By facilitating connections between academics, farmers, and community members, the project participants had an opportunity to develop a deeper analysis of food systems issues and to act on their learnings: "The collective analysis of strategies, involvement in carrying these out, successes and failures, and debates over methods and tactics have allowed the collective to generate action-derived analysis that will inform these broader theories and discourses of social change" (pp. 4-5). Other CFS partners also emphasized the ways that CCE relationships deepened their analysis and created new ways of understanding food systems issues. For example, one community co-lead explained, "Working with academics helped us think about how to frame questions and we were able to apply sociological methods to our project's various food initiatives. This partnership with the University also opened us up to new ways of looking at what we were doing."

Many CFS partners pointed to the mutually beneficial ways of knowing that both academics and community members bring to their CCE work. Multiple projects highlighted the ways that academics contributed research knowledge that produced valuable data to support community partners' experiences with food systems issues. At the same time, project partners emphasized that community perspectives contributed essential insights about people's everyday experiences, for example, in relation to developing appropriate measures to address food insecurity. One community co-lead explained,

Academics certainly have an important role to play in social change work. Although many of the community stakeholders connected to emergency food provisioning in [the region we work in] possessed a wealth of anecdotal evidence regarding the challenges facing the system, it was difficult to translate that into action. The research process was able to help in a number of ways. For example, it provided clear qualitative and quantitative evidence demonstrating some of the problems with the existing emergency food provision system, as well as a number of potential strategies for improvement. The research team was also able to integrate the opinions of local stakeholders into broader discussions from other contexts about how to most effectively combat food insecurity. 
In this case, these different knowledges about food systems issues worked together to produce a better understanding of the local food context.

While highlighting the different ways that academic and community knowledge production can be complementary, CFS partners also underlined how CCE can impact academic and community partners in different ways. For example, various CFS partners emphasized that community knowledges and experiences have an immense impact on academic work and that CBR and CSL are both dependent on it. One community colead noted that community knowledge contributes significantly to academic knowledge and theory, because community organizations and practitioners are well positioned to understand the complex issues that are moving faster than most academics can keep up with. CFS partners also noted that CCE often allows academics access to community members they might not otherwise be able to speak with, providing access to new perspectives and types of knowledge. Taken together, participants emphasized that community members and organizations involved in the CCE partnerships had an extremely positive impact on academic work by making it "more relevant," making "research actionable" (Paying for Nutrition, CFICE internal report), and providing "academic writing to a place to land, take root, and help create change" (Sharing the Table, CFICE internal report, p. 4).

In the final report for the Cross-Cultural Networks project, participants discussed the ways that CCE can impact the development of approaches to research and knowledge generation. For example, they explained how working with Indigenous communities impacted non-Indigenous academics' ability to expand their knowledge and perspectives as well as encouraged them to challenge linear knowledge production and their own research frameworks. Within the final report, project partners noted:

Non-Indigenous academic students often approach Indigenous community members with a single-minded agenda. For successful engagement, research needs to have a mutually beneficial approach. This requires the researcher to be involved with the community at an early stage, develop a positive relationship, and mutually identify all stages of the research project. ... The different perspectives and worldviews can be a complement to research, giving it depth by reflecting values, goals, and community vision.

Academics that partnered with community-based practitioners and organizations through their teaching also increased the quality of education and impacted students' ability to develop new knowledge. In CSL contexts, academics involved in project partnerships often cited the impact of the knowledge created through CCE as providing students with concrete opportunities for the enhancement and application of knowledge. For example, a student who participated in one of the CFS projects explained, "The placement gives real world, practical experience that would be great on a resume. I learned a lot about conducting interviews as well as learning about different aspects of planning such as consultations, official plan reviews, and much more." A student from a different project pointed to the importance of CCE opportunities "because students often get caught up in the theory. CSL opportunities can really help think through research proposals, about the larger political context, and how to implement ideas of social change." Similarly, an academic participant in one project explained that CCE provides opportunities for students to enact knowledge while an academic co-lead on a different project 
explained that her participation in CCE relationships has taught her "how to be more sensitive to communities' needs and the diversity of models relating to public health.”

Through these reflections, we suggest that developing collaborative knowledge was a key impact within the CFS hub's CCE partnerships. Project partners underlined the opportunities to co-create knowledge within CCE, explaining that doing so brings together diverse ways of knowing that strengthen and support one another. CFS partners also emphasized that the co-creation of knowledge can have different benefits for academics and community partners, but that a common benefit can be found in working together to prompt broader social change.

\section{CCE Impact as Building Communities of Practice}

Speaking to the impacts that CCE had in their work, CFS hub partners highlighted the value of building relationships over the long term. In this context, we use the concept "communities of practice," which refers to the sustained interactions of community-based practitioners and academics "to share knowledge and experiences and engage in collaborative action related to food systems" (Levkoe, 2017, p. 184). Through the CFS hub, this included connecting different projects and participants through existing food movement networks across Canada and beyond. In particular, CFS partners explained that relationship building occurred on a range of scales.

On an individual level, CFS partners explained that working with a large CCE project like CFICE helped to build networks by connecting them with key food movement leaders. For example, a community co-lead told us that "Connecting with [a member of the CFS Hub management team] about her B.C. experience was especially helpful for members of [our project] to understand how similar struggles unfolded in another province and to have examples to draw from in conversation with provincial government officials." These connections with food movement leaders across the country also benefited the work of members of the CFS hub management team. Writing as part of the final project evaluation, Levkoe notes,

For my own research and commitment to social change it is vital to build long-term relationships with community groups and other academics with similar tendencies. At the core of CFICE were efforts toward building long-term relationships with partners in multiple sectors. For the CFS hub this included focusing on organizations like FSC and CAFS as well as many smaller regional and provincial organizations. CFICE gave me the opportunity to engage with these organizations in a way I might not have been able to without the project's support.

CCE partnerships fostered through the CFS hub also provided the opportunity for both academic and community partners to attend a variety of regional and national food movement conferences, providing an important opportunity for developing networks. The community co-lead from one project noted that meeting other practitioners and researchers at conferences was one of the most valuable elements for her organization's participation in the CFS hub: 
Getting to go to the conferences was one of the biggest values for us including having the financial support. We had the chance to network, to go to other presentations and to present ourselves. Whereas it would be a burden just to go to a CFICE specific meeting, it was a great opportunity to gather at conferences such as FSC and CAFS. It really makes sense to convene at strategic points where people are already getting together.

An academic co-lead from another project echoed this sentiment, explaining that the face-to-face time at conferences provided space to build relationships as well as have in-depth conversations with both academics and community partners.

In addition to encouraging networking between community and academic partners within the CFS hub, CCE also provided space for the development of new relationships within the specific project partnerships. For example, the Seed Community Food Hub's final project report noted that relationships within the project changed significantly over time and identified that the resulting configuration of the relationships established between the various collaborators was a major impact of their CCE work:

When the project began, the partners were largely unfamiliar with each other, and with the contexts within which each worked. Over time, the trust and good faith between the various partners grew to such a degree that they began to consider themselves friends, as well as true colleagues pursuing a shared agenda for community change. The importance of this transformation cannot be overstated as, without it, the successes of The Seed initiative to date would have been impossible to achieve.

The Sharing the Table report also discussed measuring impact through the quality of relationships that were built over the short-, medium- and long-term. Their final report highlighted the impact of building relationships at a community level, explaining how they helped to create space where different actors came together to discuss and mobilize around key food issues in Manitoba:

The impacts of Sharing the Table could be measured by the number of relationships built among the small farmer community, and the amount of confidence increased in small farmers to speak out about their opinions and experiences, and for what they feel constitute local food systems.

At regional and provincial levels, an academic co-lead noted that through a CCE approach, she was able to develop lasting relationships with a wide range of new community partners and organizations that both enriched and went beyond her current research. She explained that she was also able to build relationships beyond her particular project, noting that she was "able to make connections with a few researchers in Ontario and in the U.S. that developed beyond the project.”

Overall, there was a consensus among participants that CCE partnerships expanded their networks, providing community practitioners and academics an opportunity to learn from and connect with others within and 
beyond their existing networks. These communities of practice helped to strengthen project partners' ability to meet their objectives, expand the focus of their work, and better develop and pursue a mutual agenda for social change. It is clear from the 12 CFS hub projects that this work would not have been visible if evaluations only measured short-term impacts. Instead, taking a context specific, relational, and process-based approach to evaluating CCE impact opened new possibilities to understand and improve their collaborative work.

\section{Discussion and Conclusions: Questioning the Impact of Impact}

The research findings presented above lead us to question the impact of impact. In most cases, assessments of CCE impact utilize (or aim to develop) standardized and rigorous measurements based on universal indicators that adhere to particular needs. Evaluation directives are typically dictated by funders or institutions that wield power over academic and/or community-based practitioners doing the work. In these cases, evaluations are often undertaken not for the researcher's or community's benefit but to satisfy a series of predetermined goals. As a result, the potential impact of CCE can be significantly diminished and, as some of the CFS partners have noted above, these kinds of evaluations often fail to meaningfully understand CCE impacts and meet community partners' needs. Building on our previous research (Kepkiewicz et al., 2018), we reiterate that CCE is complex and contested and "[we] emphasize the structural limitations of 'community first' CCE, acknowledging that 'community first' CCE is extremely difficult, if not impossible, to achieve within current academic structures" (p. 45). In other words, the political and economic context must be taken into consideration in any assessment of CCE. As a result, we must ask critical questions about the evaluation of impact, such as, Who defines impact? What is the evaluation for? What is the intended purpose?

Building on the work of critical CCE scholars and practitioners, our research from the 12 CFS projects suggests that measuring CCE must consider impact, first and foremost, in relation to the experiences of communities. Our findings demonstrate that evaluation of CCE impact must be contextual. These findings relate to a study by Jagosh et al. (2015), who explain that CCE success will look different depending on where the project takes place and who is involved. For example, our research underlines the ways that different project partners interpret successful CCE impact. While some projects concentrated on short-term concrete impacts, others considered impact as much broader and longer term. Of note, this difference in perspective often correlated with the level of institutionalization of the partnership, with more formal community-based organizations (e.g., registered nonprofit organizations) tending to define impact in more concrete terms (i.e., a report generated by students detailing an environmental scan or graphic design contributions). In contrast, CCE partnerships with more grassroots community-based organizations (e.g., informal organizations, frontline work with marginalized groups) as well as academics who drew from critical and social justice-based theory tended to understand impacts on a broader, more radical scale. These partnerships were more likely to define impact as building socially just and decolonizing movements for system-level transformation. However, it is also important to note that some partners did not 
see value in evaluating their project's impact; rather, they felt the best use of their time and energy was to concentrate on delivering necessary programs within their communities. In some contexts, it may thus be important to question whether the impact of evaluation is detrimental, taking time away from key programs.

Our research also found that the evaluation of impact must be relational in coherence with Greenhalgh, Jackson, Shaw, and Janamian (2016) argument for a focus on the ways that various partners work together to generate knowledge and action. CFS hub projects underlined the idea that the development of relationships is a key impact in and of itself as well as being an impact that often cannot (and perhaps should not) be measured in full due to its deeply personal and emotional nature. Finally, our research shows that evaluation of impact should be process based. This builds on Beckman et al.'s (2011) emphasis on CCE impact as a long-term process of accumulated outcomes that benefit the partners involved along with improving community well-being. They suggest that CCE evaluation focus not only on policy or program outcomes but also on contributions related to addressing broad community needs over time. In our research, both community and academic project partners echoed this sentiment, emphasizing the need to understand and evaluate impact based on process rather than on a specific set of predetermined factors.

Furthermore, CFS hub project partners identified impact as the development of collaborative knowledge and building networks of CCE communities of practice within the food sovereignty movement. However, within these two themes, project partners also differed in how they defined successful impact. For example, some projects focused on individual networking or networking at a community level while others pointed to building movements on a broader scale. Similarly, while some projects focused on impact as effects on the individuals and institutions involved, others focused on a systems level to consider whether CCE projects supported or hindered social change efforts. When understanding system level impacts through a food sovereignty lens, the Responsibility and Relationships final report suggests that this must include a decolonizing lens along with a social and environmental justice imperative. We recognize that measuring CCE impacts in this way can be difficult, yet our research suggests that for projects concerned with social change, CCE can be much more impactful than what can be measured by proximate experiences and perspectives in the short-term. Furthermore, our findings suggest that in order to understand the impacts of social change, it is important to do so through justice-based and anticolonial frameworks, which center diverse lived experiences and perspectives. Without these lenses, evaluations risk looking at impacts on certain groups and not others. In doing so, they may find the impact of the project to be positive when the reality includes negative outcomes. This is particularly problematic when it serves to reproduce existing inequities, as those who are in positions to define and evaluate impact often hold positions of power and privilege. With this in mind, we underline the need to ask questions such as who defines impact and impacts on whom.

In conclusion, CCE project partners must work together to define and evaluate impact in ways that are meaningful to them and that best serve collective objectives and goals. Our research findings support moves to understand CCE impact as highly contextual, relational, and process based as well as scholarly work that argues for the need to draw from justice-based frameworks to develop understandings of CCE impact. These moves are particularly important in a context where calls to evaluate research impacts are increasingly focused on standardized 
assessments and universal evaluation criteria. These moves are also important for food sovereignty projects and partnerships, which aim for broad and transformational social change. Lastly, these moves are essential in order to ensure that CCE work continues to challenge inequitable relationships and work respectfully and meaningfully with diverse communities. In this context, we encourage CCE academics and practitioners to unpack what it means to define, understand, and evaluate impact within their specific project partnerships and, in doing so, feel free to reject impact definitions and evaluations that are primarily academic exercises or a means for ingratiating CCE projects to outside institutions and funders. Furthermore, we encourage CCE practitioners to challenge ideas that measuring impact is necessarily appropriate, depending on the context and partnership goals. When evaluations of impact occur, we believe they must support CCE partners' relationships and goals and better enable CCE partnerships to understand and develop equitable relationships and broader social transformation.

\section{References}

Andrée, P., Chapman, D., Hawkins, L., Kneen, C., Martin, W., Muehlberger, C., . . \& Stroink, M. (2014). Building effective relationships for community-engaged scholarship in Canadian food studies. Canadian Food Studies/La Revue Canadienne Des études Sur L'alimentation, 1(1), $27-53$.

Andrée, P., Kepkiewicz, L., Levkoe, C. Z., Brynne, A., \& Kneen, C. (2016). Learning, food, and sustainability in community-campus engagement: Teaching and research partnerships that strengthen the food sovereignty movement. In J. Sumner (Ed.), Learning, food, and sustainability: Sites for resistance and change (pp. 133153). New York, NY: Palgrave.

Beckman, M., Penney, N., \& Cockburn, B. (2011). Maximizing the impact of community-based research. Journal of Higher Education Outreach and Engagement, 15(2), 83-103.

Block, D. R., Hague, E., Curran, W., \& Rosing, H. (2018). Measuring community and university impacts of critical civic geography: Insights from Chicago. The Professional Geographer, 70(2), 284-290.

Blouin, D. D., \& Perry, E. M. (2009). Whom does service learning really serve? Community-based organizations' perspectives on service learning. Teaching Sociology, 37(2), 120-135.

Bortolin, K. (2011). Serving ourselves: How the discourse on community engagement privileges the university over the community. Michigan Journal of Community Service Learning, 18(1), 49-58.

Bringle, R. G., \& Hatcher, J. A. (2002). Campus-community partnerships: The terms of engagement. Journal of Social Issues, 58(3), 503-516.

Cahuas, M. C., \& Levkoe, C. Z. (2017). Towards a critical service learning in geography education: exploring challenges and possibilities through testimonio. Journal of Geography in Higher Education, 41(2), 246-263.

Celio, C. I., Durlak, J., \& Dymnicki, A. (2011). A meta-analysis of the impact of service-learning on students. Journal of Experiential Education, 34(2), 164-181.

CFICE. (n.d.). About CFICE. Retrieved from https://carleton.ca/communityfirst/about

Collins, S. E., Clifasefi, S. L., Stanton, J., The LEAP Advisory Board, Straits, K. J. E., Gil-Kashiwabara, E., . . \& \& 
Wallerstein, N. (2018). Community-based participatory research (CBPR): Towards equitable involvement of community in psychology research. American Psychologist, 73(7), 884-898.

Cronley, C., Madden, E., \& Davis, J. B. (2015). Making service-learning partnerships work: Listening and responding to community partners. Journal of Community Practice, 23(2), 274-289.

Cruz, N. I., \& Giles, D. E., Jr. (2000). Where's the community in service-learning research? Michigan Journal of Community Service Learning, 7, 28-34.

Curwood, S. E., Munger, F., Mitchell, T., Mackeigan, M., \& Farrar, A. (2011). Building Effective CommunityUniversity Partnerships: Are Universities Truly Ready? Michigan Journal of Community Service Learning, $17(2), 15-26$.

Duryea, M., Hochman, M., \& Parfitt, A. (2007, February). Measuring the impact of research. Research Global, $8-21$.

Eyler, J. S., Giles, D. E., Jr., Stenson, C. M., \& Gray, C. J. (2001). At a glance: What we know about the effects of service-learning on college students, faculty, institutions and communities, 1993-2000: Third Edition. Retrieved from http://www.compact.org/wp-content/uploads/resources/downloads/aag.pdf

FSC [Food Secure Canada]. (n.d.). Who we are. Retrieved from https://foodsecurecanada.org/who-we-are

Grain, K. M., \& Lund, D. (2016). The social justice turn: Cultivating "critical hope" in a time of despair. Michigan Journal of Community Service Learning, 23(1), 45-59.

Greenhalgh, T., Jackson, C., Shaw, S., \& Janamian, T. (2016). Achieving research impact through co-creation in community-based health services: Literature review and case study. The Millbank Quarterly, 94(2), 392-429.

Guta, A., Flicker, S., \& Roche, B. (2013). Governing through community allegiance: A qualitative examination of peer research in community-based participatory research. Critical Public Health, 23(4), 432-451.

Impact. (n.d.). Impact in community-based research, as discussed at the 2014 National Summit. Retrieved from https://www.communitybasedresearch.ca/resources/677-National-Summit/Impact-Jan-27.pdf (Accessed on March 30 2019)

Jagosh, J., Bush, P. L., Salsberg, J., Macaulay, A. C., Greenhalgh, T., Wong, G., . . \& Pluye, P. (2015). A realist evaluation of community-based participatory research: partnership synergy, trust building and related ripple effects. BMC Public Health, 15(1).

Kemmis, S., \& McTaggart, R. (2005). Participatory action research. In N. K. Denzin and Y. S. Lincoln (Eds.), Handbook of qualitative research (3rd ed., pp. 559-603). Thousand Oaks, CA: Sage Publications.

Kepkiewicz, L., Levkoe, C. Z., \& Brynne, A. (2018). "Community first” for whom? Reflections on the possibilities and challenges of community-campus engagement from the Community Food Sovereignty Hub. Engaged Scholar Journal, 4(2), 43-60.

Kepkiewicz, L., Srivastava, R., Levkoe, C. Z., Brynne, A., \& Kneen, C. (2017). Community Engaged action research and food sovereignty in Canada. In Peoples Knowledge Editorial Collective (Eds.), Everyday experts: How people's knowledge can transform the food system (pp. 292-307). Coventry, UK: Coventry University.

Levkoe, C. Z. (2017). Communities of food practice: Regional networks as strategic tools for food systems 
transformation. In I. Knezevic, A. Blay-Palmer, C. Z. Levkoe, P. Mount, \& E. Nelson (Eds.), Nourishing communities: From fractured food systems to transformative pathways (pp. 183-200). New York, NY: Springer.

Levkoe, C. Z., Andrée, P., Bhatt, V., Brynne, A., Davison, K. M., Kneen, C., \& Nelson, E. (2016). Collaboration for transformation: Community-campus engagement for just and sustainable food systems. Journal of Higher Education Outreach and Engagement, 20(3), 23-61.

Levkoe, C. Z., Brem-Wilson, J., \& Anderson, C. R. (2019). People, power, change: Three pillars of a food sovereignty research praxis. The Journal of Peasant Studies, 46(7), 1389-1412.

Levkoe, C. Z., Erlich, S., \& Archibald, S. (2019). Campus food movements and community service-learning: Mobilizing partnerships throughout the Good Food Challenge in Canada. Engaged Scholar Journal: Community-Engaged Research, Teaching, and Learning, 5(1), 57-76.

MacLeod, M. A., \& Emejulu, A. (2014). Neoliberalism with a community face? A critical analysis of asset-based community development in Scotland. Journal of Community Practice, 22(4), 430-450.

Marullo, S., \& Edwards, B. (2000). From charity to justice: The potential of university-community collaboration for social change. American Behavioral Scientist, 43(5), 895-912.

Mitchell, T. D. (2007). Critical service-learning as social justice education: A case study of the citizen scholars program. Equity $\Xi^{\circ}$ Excellence in Education, 40(2), 101-112.

Mitchell, T. D. (2008). Traditional vs. critical service-learning: Engaging the literature to differentiate two models. Michigan Journal of Community Service Learning, 14(2), 50-65.

Mitchell, T. D., Donahue, D. M., \& Young-Law, C. (2012). Service learning as a pedagogy of whiteness. Equity E' Excellence in Education, 45(4), 612-629.

Ochocka, J., \& Janzen, R. (2014). Breathing life into theory: Illustrations of community-based researchHallmarks, functions, and phases. International Journal of Community Research and Engagement, 7(1), 1833.

Penfield, T., Baker, M. J., Scoble, R., \& Wykes, M. C. (2014). Assessment, evaluations, and definitions of research impact: A review. Research Evaluation, 23(1), 21-32.

Phipps, D. (2011). A report detailing the development of a university-based knowledge mobilization unit that enhances research outreach and engagement. Scholarly and Research Communication, 2(2), 1-13.

Sheridan, M. P., \& Jacobi, T. (2014). Critical feminist practice and campus-community partnerships: A review essay. Feminist Teacher, 24(1-2), 138-150.

Srinivas, T., Meenan, C. E., Drogin, E., \& DePrince, A. P. (2015). Development of the Community Impact Scale measuring community organization perceptions of partnership benefits and costs. Michigan Journal of Community Service Learning, 21(2), 5-21.

Taylor, S. M., \& Ochocka, J. (2017). Advancing community-based research in Canada. International Journal of Knowledge-Based Development, 8(2), 183-200.

Trickett, E. J., \& Beehler, S. (2017). Participatory action research and impact: An ecological ripples perspective. Educational Action Research, 25(4), 525-540. 
Varcoe, C. (2006). Doing participatory action research in a racist world. Western Journal of Nursing Research, $28(5), 525-540$.

Verjee, B. (2012). Critical race feminism: A transformative vision for service-learning engagement. Journal of Community Engagement and Scholarship, 5(1), 57-69.

Vernon, A., \& Ward, K. (1999). Campus and community partnerships: Assessing impacts and strengthening connections. Michigan Journal of Community Service Learning, 6(1), 30-37.

Ward, K., \& Wolf-Wendel, L. (2000). Community-centered service learning. American Behavioral Scientist, 43(5), 767-780.

Wiebe, S. M., \& Taylor, S. M. (2014). Community-based research Canada: Background paper. CCCR National Summit Backgrounder. Retrieved from https://bit.ly/2GjHe26 (Accessed on March 30, 2019)

\section{Authors}

CHARLESZ. LEVKOE is the Canada Research Chair in Sustainable Food Systems, the Director of the Sustainable Food Systems Lab and an Associate Professor in the Department of Health Sciences at Lakehead University in Ontario. His community engaged research uses a food systems lens to better understand the importance of, and connections between social justice, ecological regeneration, regional economies, and active democratic engagement.

LAUREN KEPKIEWICZ is a community-based researcher with the Bow Valley Food Alliance and a postdoctoral researcher at the University of Calgary. She is involved in the National Farmers Union Indigenous Solidarity Working Group and the Bow Valley Food Charter. She also spent several years as the research assistant for the Community First: Impacts of Community Engagement (CFICE) Community Food Security/Sovereignty hub. 